\title{
Bases celulares da remodelação óssea e avaliação de pacientes com redução de densidade mineral óssea em radiografias odontológicas
}

\author{
Bone remodeling cellular basis and reduced bone mineral \\ density patient screening on dental radiographs
}

\author{
LORRAINE PERCILIANO DE FARIA ${ }^{1}$ \\ CHRISTYAN HIROSHI IIDA ${ }^{2}$ \\ MARIANA MURAI CHAGAS ${ }^{3}$ \\ JOSÉ PIMENTEL GIRARD ${ }^{4}$ \\ Sergio XaVier VilLagomez VilLAfuerte ${ }^{5}$ \\ LUCIANA MUNHOZ \\ EMIKO SAITO ARITA
}

\section{RESUMO}

Objetivo: O objetivo primário desta revisão bibliográfica foi prover o Cirurgião-Dentista de informações sobre a utilização de radiografias odontológicas, para a avaliação de pacientes com risco de desenvolvimento de osteoporose. Foram incluídos nesta revisão artigos referentes ao uso de radiografias odontológicas, para rastreamento da osteoporose, de 1994 até 2019, publicados exclusivamente na base de dados PUBMED. Resultados: A osteoporose é uma doença sistêmica que afeta o metabolismo ósseo, alterando sua microarquitetura e diminuindo a densidade mineral óssea (DMO), sem produzir variações em sua composição química. Essa entidade patológica afeta preferencialmente ossos com grande quantidade de tecido ósseo trabecular, como a mandíbula. A redução da densidade mineral óssea da mandíbula pode ser verificada por meio de radiografias odontológicas, panorâmicas e periapicais. A diminuição da densidade óssea na mandíbula é um dos sinais de alerta de osteoporose.

Conclusões: É essencial que o Cirurgião-Dentista possa avaliar criticamente a qualidade óssea da mandíbula, incluindo seus aspectos biológicos e radiográficos, para o planejamento adequado dos tratamentos e eventual detecção de pacientes com risco de desenvolvimento da doença.

Palavras-chave: Osteoporose. Densidade mineral óssea. Radiografia panorâmica. Remodelação óssea.

\begin{abstract}
Aim: The primary objective of this literature review was to provide the dental professional information about the use of dental radiographs, to screen patients at risk of developing osteoporosis. This review included articles on the use of dental radiographs for osteoporosis screening, from 1994 to 2019, published exclusively in the PUBMED database.

Results: It is essential that the dental surgeon can critically evaluate the bone quality of the mandible, including its biological and radiographic aspects, for proper treatment planning and screening of patients at risk of disease development.

Conclusions: It is essential that the dental surgeon be able to evaluate bone quality, including its biological and radiographic aspects, for the proper planning of future treatments and inclusive to suspect of osteoporosis. Keywords: Osteoporosis. Bone mineral density. Bone remodeling. Panoramic radiographs.
\end{abstract}

\footnotetext{
Departamento de Biomateriais e Biologia Oral, Faculdade de Odontologia da Universidade de São Paulo. E-mail: Iorrainepfaria@usp.br

12 Departamento de Diagnóstico Bucal, Radiologia Odontológica e Imaginologia, Faculdade de Odontologia da Universidade de São Paulo. E-mail: christyan.iida@usp.br

3 Departamento de Estomatologia, Faculdade de Odontologia da Universidade de São Paulo. E-mail: mariana.chagas@usp.br

Departamento de Prótese, Faculdade de Odontologia da Universidade de São Paulo. E-mail: girard@usp.br

5 Departamento de Diagnóstico Bucal, Radiologia Odontológica e Imaginologia, Faculdade de Odontologia da Universidade de São Paulo. E-mail: sergiovgz@usp.br

6 Departamento de Diagnóstico Bucal, Radiologia Odontológica e Imaginologia, Faculdade de Odontologia da Universidade de São Paulo. E-mail: dra.lucimunhoz@usp.br

7 Departamento de Diagnóstico Bucal, Radiologia Odontológica e Imaginologia, Faculdade de Odontologia da Universidade de São Paulo. E-mail: esarita@usp.br
} 


\section{INTRODUÇÃO}

O osso sofre constantes remodelações ao longo da vida a fim de manter o equilíbrio tecidual fisiológico adequado. Esse processo ocorre por meio da atividade de osteoclastos, reabsorvendo osso, e de osteoblastos, neoformando osso, resultando não somente em alterações na quantidade, mas também na qualidade óssea. ${ }^{1}$

A qualidade óssea é designada como um somatório de características que influenciam na resistência à fratura do osso. Tais características estão relacionadas à forma e geometria óssea, à organização tridimensional das trabéculas (microarquitetura), à existência de microdanos e qualidade dos componentes da matriz extracelular óssea. ${ }^{2,3}$

A quantidade de tecido ósseo se refere à densidade mineral óssea (DMO), cuja avaliação é feita principalmente pelo exame de densitometria óssea utilizando a técnica de absorciometria com Raios-X com duplaenergia (DXA). Esse exame é considerado padrão ouro para identificação de osteoporose devido a sua alta precisão, baixa exposição à radiação e rapidez. ${ }^{4}$

A osteoporose é uma doença sistêmica que afeta o metabolismo ósseo, alterando sua microarquitetura e diminuindo a DMO, sem produzir variações em sua composição química. A principal consequência negativa da osteoporose são as fraturas por fragilidade óssea, que podem levar seus pacientes a quadros de morbidade ou mortalidade. O paciente acometido por uma fratura osteoporótica não evolui com mortalidade por conta da fratura propriamente dita, mas por conta das complicações advindas dessa fratura, por exemplo, embolias, complicações em cirurgias ortopédicas, entre outros.

Embora a DXA seja um exame primordial no diagnóstico da osteoporose, não é um exame amplamente acessível e, por muitas vezes, relativamente caro para populações de baixa renda. Por conta disso, tem-se pesquisado exaustivamente a utilização de outros exames de imagem no rastreamento de pacientes com risco à redução da densidade mineral óssea; ${ }^{5}$ um desses exames de imagem é a radiografia panorâmica. ${ }^{6}$

A radiografia panorâmica é um exame com frequência solicitado pelo cirurgiãodentista, com finalidade de avaliar as estruturas dento-maxilo-faciais, que apresenta baixa dose de radiação e baixo custo. Mostra a possibilidade de análise das estruturas faciais, permitindo verificar indícios de redução da densidade mineral óssea, especialmente na mandíbula. ${ }^{7} \mathrm{~A}$ utilização da radiografia panorâmica no rastreamento de pacientes sob risco de redução da DMO parte da premissa que as alterações osteometabólicas sistêmicas também afetam os ossos craniofaciais, em especial a cortical da mandíbula. ${ }^{6}$

A redução da densidade mineral óssea sistêmica e local apresenta implicações diretas na odontologia, especialmente no resultado de procedimentos que dependem da remodelação adequada do tecido ósseo. Ademais, o cirurgião-dentista pode, no momento que solicita uma radiografia panorâmica para fins odontológicos, identificar pacientes sob risco de osteoporose encaminhando-os para tratamento adequado, antes que esses pacientes apresentem fraturas osteoporóticas. ${ }^{8}$

Dessa forma, o objetivo desta revisão da literatura é fornecer bases biológicas e radiográficas que permitam ao cirurgiãodentista conhecer e identificar as alterações no tecido ósseo e, assim, avaliar a sua qualidade em radiografias panorâmicas, contribuindo para a saúde sistêmica do paciente e melhorando a previsibilidade de tratamentos odontológicos que dependem da remodelação do tecido ósseo. 
BASES CELULARES DA REMODELAÇÃo ÓSSEA E AVALIAÇÃo DE PACIENTES

COM REDUÇÃO DE DENSIDADE MINERAL ÓSSEA EM RADIOGRAFIAS ODONTOLÓGICAS

\section{MATERIAIS E MÉTODOS}

Para facilitar o entendimento deste artigo, é inicialmente aqui apresentada uma noção geral da estrutura do tecido ósseo, com o processo de sua remodelação.

\section{Tecido ósseo e sua remodelação}

O osso é um tecido conjuntivo especializado e mineralizado, responsável pelo suporte de estruturas, proteção de órgãos vitais e locomoção. Além disso, o tecido ósseo é um importante reservatório de íons e minerais, como o cálcio e fosfato. ${ }^{12}$

A sua composição peculiar, formada por uma matriz orgânica e um componente mineral, permite capacidade de remodelação desse tecido. A matriz orgânica é composta principalmente por colágeno do tipo I, enquanto a matriz mineral é formada primordialmente por cristais de hidroxiapatita $\left[3 \mathrm{Ca}_{3}\left(\mathrm{PO}_{4}\right)_{2}(\mathrm{OH})_{2}\right]$. Apesar de, macroscopicamente, essa organização se dispor formando uma densa camada externa de tecido ósseo compacto, denominada de cortical óssea, e internamente, por um tecido ósseo trabecular preenchido por medula óssea, ambas as camadas possuem a mesma composição química e celular. ${ }^{13}$

No tecido ósseo há duas linhagens celulares que originam diferentes tipos de células, que são: as células de origem ectomesenquimal (osteoblastos, células de revestimento ósseo e osteócitos), que são responsáveis por regular a secreção de matriz orgânica; e as de origem monocítica/ macrofágica (osteoclastos), que têm a função de reabsorção óssea. ${ }^{14}$

O processo contínuo de neoformação de tecido ósseo e de sua reabsorção é conhecido como remodelação óssea. Esse fenômeno é essencial para promover o crescimento, o reparo de microfraturas, a movimentação dentária e adaptação a novas necessidades fisiológicas do osso.
O ciclo da remodelação ocorre em três fases: reabsorção óssea, reversão e neoformação. A reabsorção, realizada pelos osteoclastos, é mediada localmente pelo sistema RANK-RANKL-OPG. Na membrana plasmática dos precursores monocíticos das células clásticas, há um receptor NF-kb RANK (receptor activator of nuclear factor kappa $B)$, que quando ativado pelo seu ligante $o$ RANK-L (receptor activator of nuclear factor kappa B ligand), uma proteína secretada pelos osteoblastos, osteócitos e seus precursores no osso, estimulam as respostas moleculares que promovem a diferenciação das células clásticas. O controle desse processo é mediado pela osteoprotegerina (OPG). Quando é necessário que o estímulo de diferenciação dos osteoclastos cesse, ocorre a liberação da OPG pelas células da linhagem osteoblástica. A OPG se liga ao RANKL, impedindo sua ligação ao RANK e inibindo os processos de diferenciação e ativação das células clásticas. ${ }^{15}$

Cessados os estímulos para a reabsorção, inicia-se o processo de reversão. Nessa fase, osteoblastos em diferenciação e osteoblastos já diferenciados, depositam uma camada muito fina de proteínas não-colágenas, como a osteopontina e sialoproteína óssea. Essa camada tem propriedades adesivas, que permitem que a nova camada de osso a ser formada tenha uma boa adesão à superfície óssea recém-reabsorvida. ${ }^{16}$ Essa camada é conhecida como linha de cimentação ou linha de reversão; sua visualização é possível por meio de análises microscópicas, não sendo visível radiograficamente.

$\mathrm{Na}$ sequência, osteoblastos já diferenciados começam a secretar a matriz orgânica e à medida que essa deposição vai ocorrendo, alguns osteoblastos ficam retidos na matriz, convertendo-se em osteócitos. Essas células mantêm uma profusa rede de comunicação entre elas, permitindo que os sinais para a remodelação alcancem todos os microambientes do tecido ósseo (Figura 1). ${ }^{16}$ 
4) Repouso

Osteoblastos se tornam células de revestimento ósseo.
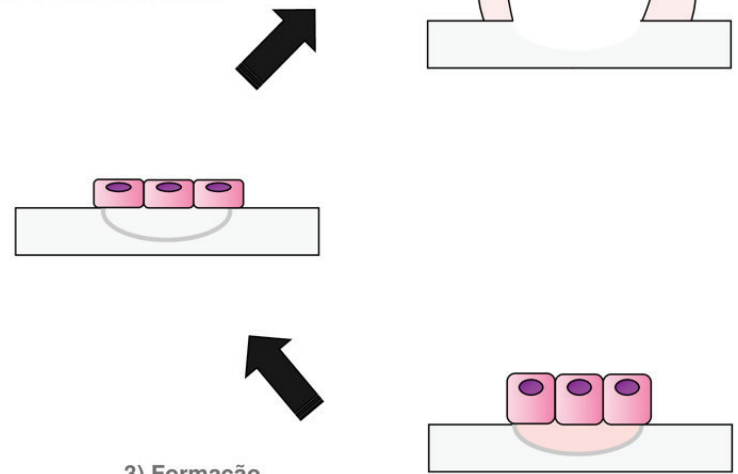

3) Formação

Novo tecido é depositado
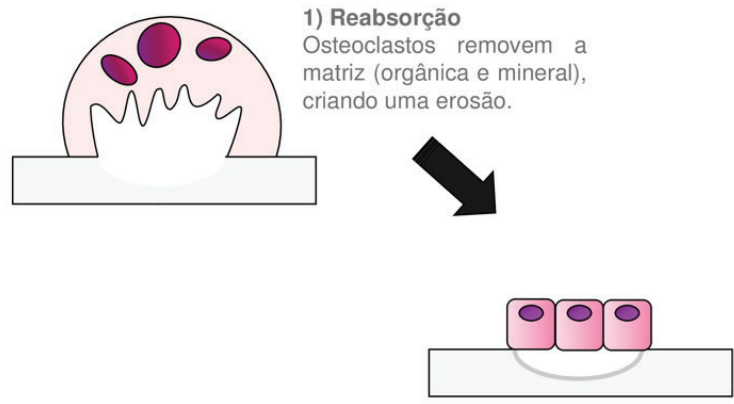

2) Reversão

Osteoblastos depositam

uma linha cimentante,

composta principalmente

por Osteopontina

Sialoproteínas.

Figura 1 - Etapas da remodelação óssea.

Diversos fatores locais e sistêmicos podem influenciar os processos de remodelação óssea, podendo promover uma remodelação fisiológica ou patológica. Em situações de normalidade o osso é reabsorvido e neoformado em proporção semelhante, mantendo sua forma e função. Quando existe um desequilíbrio nesses processos, por exemplo na osteoporose, há uma maior liberação de estímulos reabsortivos, levando à perda de massa óssea. Fatores como o paratormônio (PTH), prostaglandina (PGE2), interleucinas (IL-1, IL-6) e glicocorticóides estimulam a ação das células clásticas, aumentando a reabsorção óssea; enquanto que o estrogênio, calcitonina e cálcio promovem uma inibição dos estímulos reabsortivos e estimulam a neoformação. ${ }^{17}$

\section{Análise de pacientes com redução da densidade mineral óssea em Odontologia, com uma discussão dos resultados encontrados nesta revisão de literatura}

A motivação principal desta revisão da literatura foi demonstrar ao cirurgiãodentista formas simples de rastrear pacientes com redução da densidade mineral óssea, utilizando radiografias odontológicas, além de enumerar as principais técnicas que podem ser amplamente aplicadas, sem a necessidade de uso de ferramentas adicionadas, criadas para a Odontologia.

O osso alveolar mandibular, referência à condição óssea corporal do indivíduo, apresenta uma remodelação óssea rápida e reflete a redução da DMO sistêmica. A redução da DMO mandibular pode ser verificada por meio de exames radiográficos odontológicos. A radiografia panorâmica é o exame radiográfico que apresenta a maior possibilidade de aplicação de várias análises de rastreamento oportunista de pacientes sob risco de osteoporose. Essas análises realizadas em radiografias são denominadas "radiomorfometrias" e resultam em "índices radiomorfométricos". Esses índices tanto podem ser de natureza qualitativa, na qual existe uma avaliação visual do exame radiográfico, ou mesmo quantitativa, na qual se medem regiões específicas da radiografia com o intuito de se verificar a DMO. Os principais índices radiomorfométricos citados em literatura compreendem os índices desenvolvidos por Lindh e colaboradores, ${ }^{11}$ Klemetti e colaboradores ${ }^{9}$ e Taguchi e 
colaboradores ${ }^{10}$ e são aferidos por meio de exames radiográficos panorâmicos.

A avaliação proposta por Lindh e colaboradores, ${ }^{11}$ e modificada por Jonasson e colaboradores, ${ }^{18}$ classifica o trabeculado ósseo mandibular como: esparso, trabeculado denso e esparso alternado ou trabeculado denso ${ }^{18}$ (Figura 2 e desenho esquemático na Figura 3).

Uma densa trabeculação no processo alveolar, sem alterações ósseas induzidas por inflamação, é um forte indicador de alta $\mathrm{DMO}$, enquanto uma trabeculação esparsa prediz redução da $\mathrm{DMO} \cdot{ }^{19} \mathrm{Embora}$ as variáveis mandibulares identifiquem indivíduos com baixa $\mathrm{DMO}$, elas não são suficientemente discriminantes para o diagnóstico de osteoporose, mas o mais importante é que o padrão trabecular mandibular é uma ferramenta funcional para identificar alto risco de fratura esquelética. ${ }^{18,20,21}$ e indicação de necessidade de investigação por meio da DXA.
A)

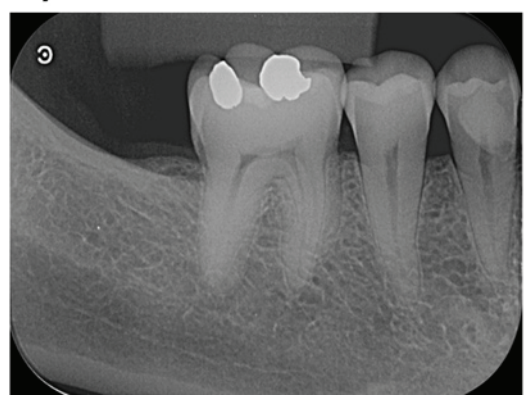

B)

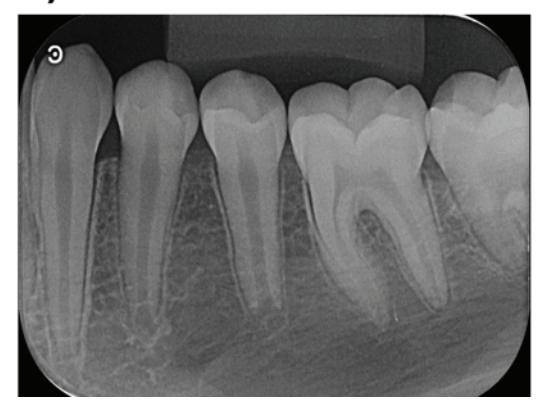

C)

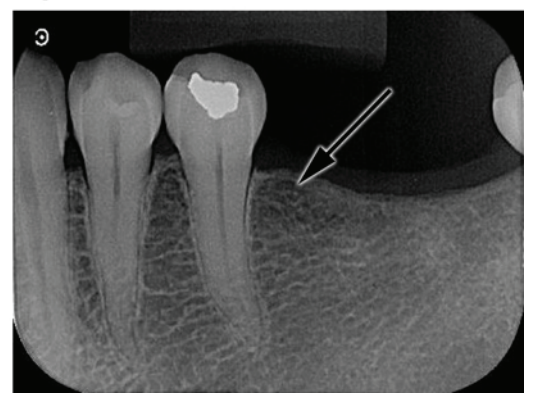

Figura 2 - Radiografias de referência para avaliação do osso trabecular. Em (A), radiografia periapical de um paciente em condições normais, com o trabeculado ósseo denso, sem alterações na qualidade óssea. Em (B), radiografia periapical de paciente com osteoporose, observamos um trabeculado ósseo mais esparso e trabéculas finas. Em (C), radiografia periapical de paciente com osteopenia, observamos trabeculado esparso, baixa densidade óssea, trabéculas finas e rarefação óssea, sinalizada pela seta preta.

A

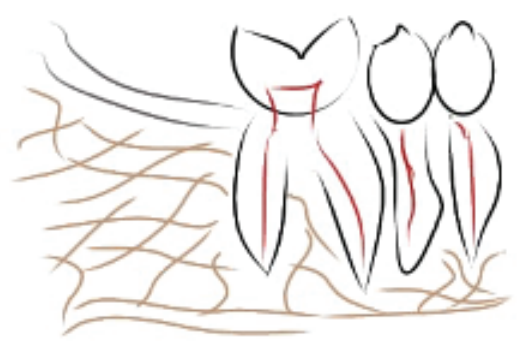

B

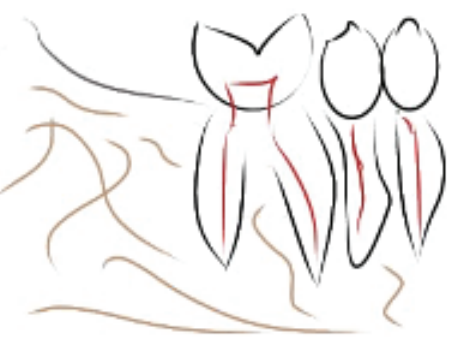

C

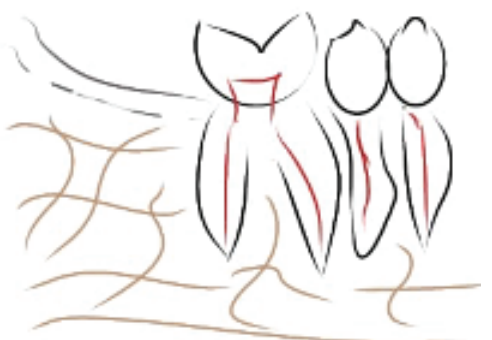

Figura 3 - Desenho esquemático da classificação de Lindh e colaboradores, ${ }^{11}$ na qual se analisa qualitativamente o padrão do trabeculado ósseo por meio da radiografia periapical. Em (A), desenho esquemático radiografia periapical com padrão trabecular normal. Em (B), desenho esquemático de radiografia periapical com osteoporose, com trabeculado ósseo moderadamente esparso. Em (C), desenho esquemático de radiografia periapical com redução da densidade mineral óssea (osteopenia), com trabeculado ósseo sutilmente esparso. As trabéculas ósseas são representadas em marrom na presente figura. 
Essa análise qualitativa do padrão trabecular ósseo em radiografias periapicais foi também idealizada para radiografias panorâmicas posteriormente por Taguchi e colaboradores, ${ }^{22}$ que mencionaram que quanto mais esparso o padrão trabecular, tanto maior o risco do paciente ser portador de redução da densidade mineral óssea. Os autores classificaram, semelhantemente a Lindh e colaboradores, ${ }^{11}$ o padrão trabecular em cinco categorias, do mais esparso ao mais denso. Taguchi e colaboradores ${ }^{22}$ verificaram que existia correlação entre sua classificação visual qualitativa para o padrão trabecular em radiografias panorâmicas e exames de tomografia computadorizada, utilizandose das unidades Housfield (HU) para aferir tal correlação. ${ }^{22}$ Todavia, não analisaram a correlação da técnica com o exame de DXA. ${ }^{22}$ Essa classificação foi excluída da revisão de literatura por ter poucas citações e somente um artigo original pesquisou sua correlação com a densitometria óssea. ${ }^{23}$ Embora a técnica de Taguchi e colaboradores ${ }^{22}$ tenha sido sugerida em 1994, somente em 2019 buscou-se verificar sua correlação com a DXA. Entretanto, Munhoz e colaboradores, ${ }^{23}$ ao analisar se o padrão trabecular ósseo em radiografias panorâmicas apresentava alguma correlação com a DXA, não obtiveram resultados com significância estatística.

Com uma abordagem diferente da técnica de Taguchi e colaboradores, ${ }^{22}$ mas também utilizando-se de radiografias panorâmicas, Klemetti e colaboradores $^{9}$ classificaram o padrão de densidade óssea cortical da mandíbula, analisando a presença de erosões ósseas ou defeitos ósseos, definidos como áreas radiolúcidas semilunares, circulares ou lineares na cortical da mandíbula, na região desde o forame mentual até o segundo pré-molar inferior.

Os autores propuseram uma classificação da presença e quantidade de defeitos ósseos na cortical da mandíbula na qual a cortical é definida de três formas: $\mathrm{C} 1$, C2 e C39 (Figura 4 com desenho esquemático na Figura 5):
- C1 - a margem endóssea da cortical regular é definida em ambos os lados;

- C2 - a margem endóssea apresentava defeitos semilunares (reabsorção lacunar) ou parecendo formar corticais residuais em um ou nos dois lados;

- C3 - a camada cortical formada por muitos resíduos de cortical e extremamente poroso.

A classificação de Kemetti é denominada de "índice da cortical mandibular" e sua correlação com a DXA foi exaustivamente comprovada.4,6-8,23,24 Na revisão sistemática de Calciolari e colaboradores, ${ }^{24}$ após a avaliação de 27 estudos que utilizaram o índice de Klemetti, os autores observaram que a presença de qualquer tipo de erosão cortical (índices C2 e C3) pode ser um indicativo DMO reduzida, sendo associados a pelo menos à osteopenia. É uma técnica de rastreamento de pacientes sob risco de redução da densidade mineral óssea de fácil aplicabilidade para cirurgiões-dentistas, tendo em vista que classifica qualitativamente radiografias panorâmicas que são largamente solicitadas por cirurgiões-dentistas no dia a dia da prática odontológica.

Outra forma de avaliar o risco da redução da DMO é medir a espessura da cortical da mandíbula. Taguchi e colaboradores ${ }^{10}$ se propuseram a medir a espessura da cortical da mandíbula em duas áreas distintas: abaixo do forame mentual e na região de ângulo. $O$ índice mentual, que é a medida da cortical da mandíbula abaixo do forame mentual, é classificado como adequado se for maior do que 3.1 milímetros e como redução da DMO se for menor do que esse valor (desenho esquemático na Figura 7). Esse índice, com o índice da cortical mandibular, foi amplamente estudado $4,6-8,23,24$ e pode ser caracterizado por um índice quantitativo, ao contrário de índice da cortical mandibular, que é qualitativo. Apresenta correlação comprovada com a DXA, verificada pelos próprios desenvolvedores da técnica ${ }^{10} \mathrm{e}$ outros pesquisadores, ${ }^{7,22,24}$ assim como simples aplicabilidade, bastando que o cirurgião-dentista utilize algum instrumento de medida (como uma régua endodôntica, por exemplo), para checar a cortical mandibular, tendo o cuidado de verificar se a radiografia panorâmica se apresenta em proporção 1 por 1. 
C1

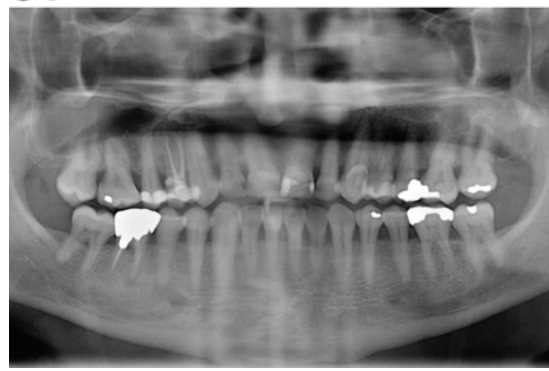

C2

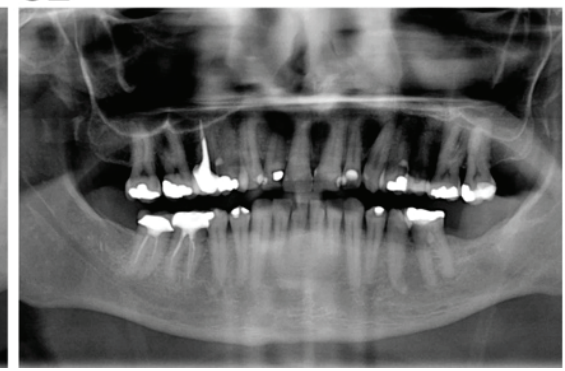

C3

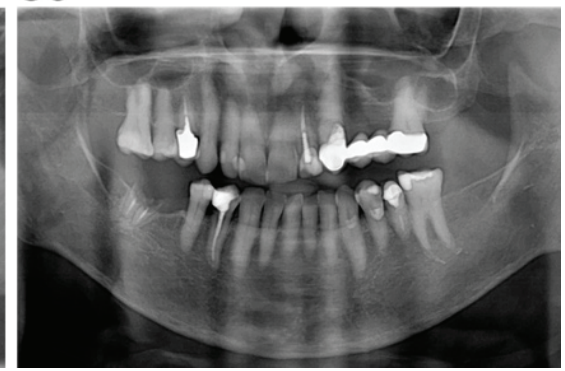

Figura 4 - Classificação qualitativa da cortical mandibular em radiografia panorâmica de mulheres pós-menopausa. A - C1: Cortical com ausência de erosões; B - C2: Cortical com erosão leve a moderada; C - C3: Cortical com erosão acentuada.
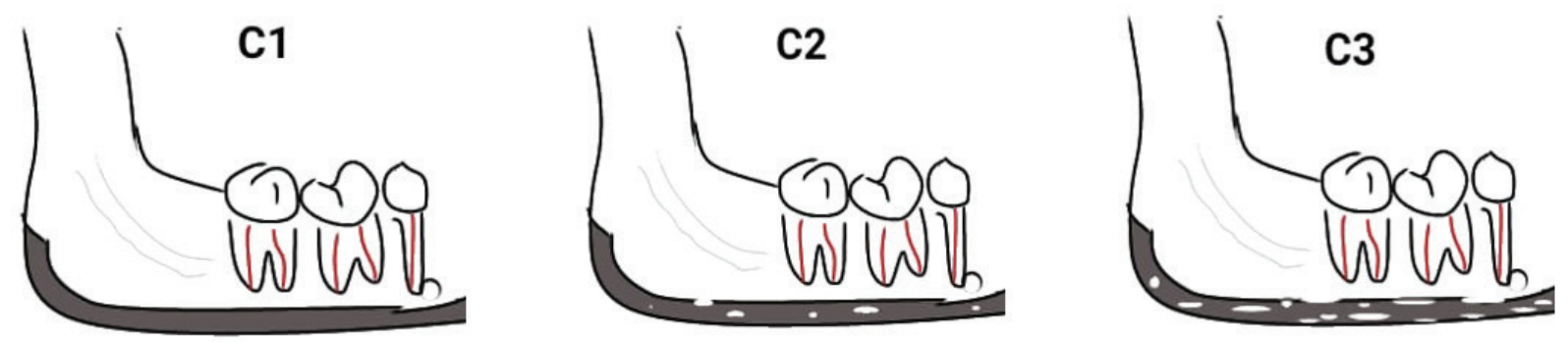

Figura 5 - Desenho esquemático da classificação qualitativa da cortical mandibular em radiografia panorâmica proposto por Klemetti e colaboradores. ${ }^{9} \mathrm{~A}-\mathrm{C} 1$ : Cortical com ausência de erosões; $\mathrm{B}$ C2: Cortical com erosão leve a moderada; C - C3: Cortical com erosão acentuada.

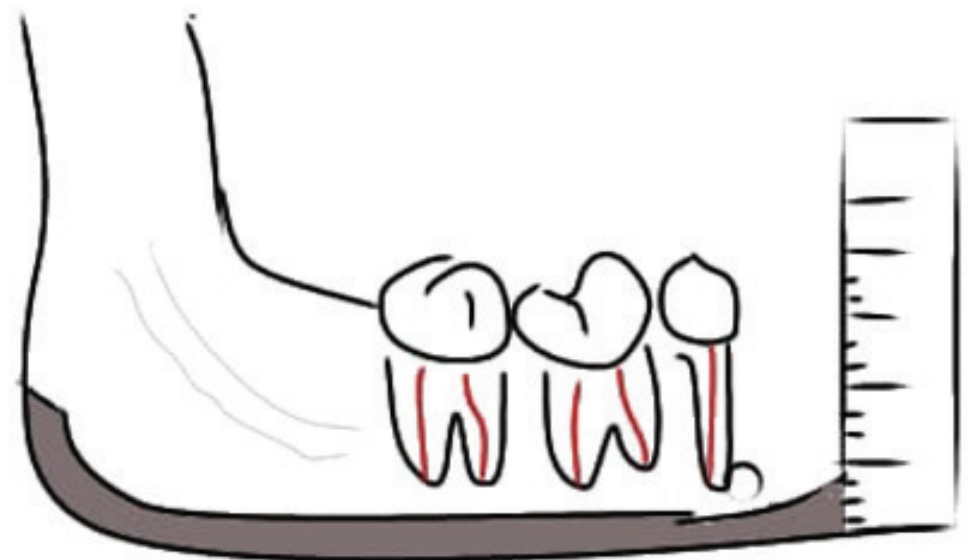

Figura 6 - Desenho esquemático da classificação proposta por Taguchi e colaboradores. ${ }^{10}$ Por meio dessa técnica, o cirurgião-dentista deve medir a espessura da cortical da mandíbula abaixo do forame mentual. Se a cortical exibir espessura menor do que 3.1 milímetros, existe indício de que o paciente em questão pode apresentar redução da densidade mineral óssea. 
Para esta revisão, foram consultados artigos abrangendo uso de radiografias odontológicas para o rastreamento de pacientes sob o risco de redução da densidade mineral óssea na base de dados PUBMED, a partir do ano de 1994 até o presente momento (2019). O ano de 1994 foi escolhido como ano inicial da busca por conta da publicação oficial do índice da cortical mandibular, desenvolvido por Klemetti e colaboradores. ${ }^{9}$

As palavras-chave inicialmente utilizadas na busca bibliográfica foram: Mandibular osteoporosis AND Dual x-ray absorptiometry. Sequencialmente, os artigos encontrados nesta primeira busca foram agrupados usando-se as seguintes palavras-chave: Dual x-ray absorptiometry AND Panoramic radiograph; Dual x-ray absorptiometry AND Cone beam computed tomograph; Dual x-ray absorptiometry AND Multislice computed tomograph; Dual x-ray absorptiometry AND Periapical radiograph; Dual x-ray absorptiometry AND Ultrassonograph; Dual x-ray absorptiometry AND computed tomograph AND panoramic radiograph. Um esquema "flow chart" do resultado dessa busca, encontra-se disponível na Figura 7.

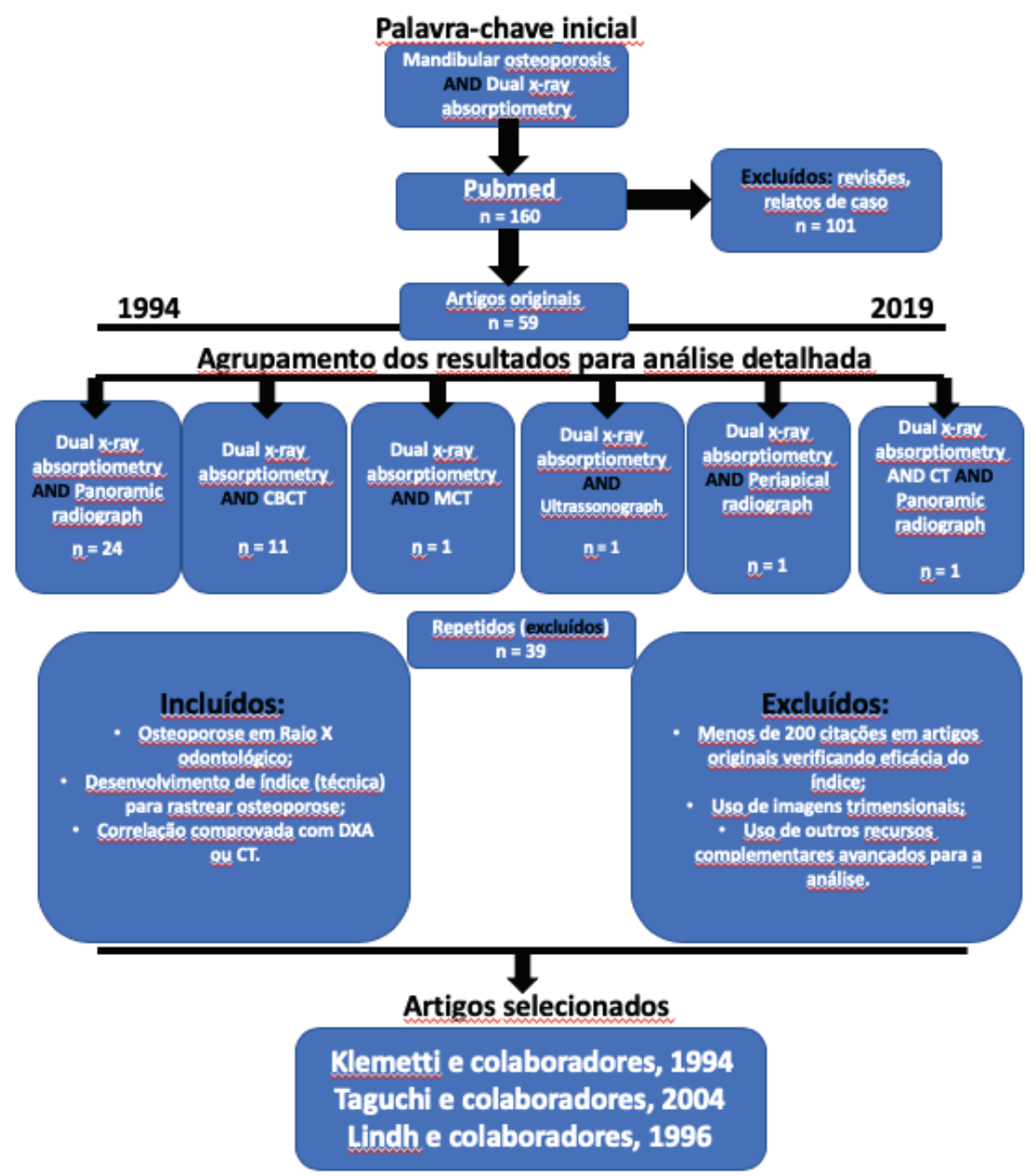

Figura 7 - Fluxograma com resultados obtidos na busca com as palavras-chave inicial e os resultados, após agrupamento dos trabalhos pós-busca.

Abreviações: $\mathrm{MCl}$ : índice da cortical mandibular; CBCT: tomografia computadorizada cone beam; MCT: tomografia computadorizada multislice 
Foram incluídos no resultado final artigos que criaram e descreveram índices radiomorfométricos que permitem que 0 cirurgião-dentista identifique pacientes sob risco de osteoporose em radiografias odontológicas. Entretanto, somente foram incluídos no resultado final estudos que, além de desenvolver um índice, ainda comprovaram que esse índice apresentava correlação significativa com a densitometria óssea ou tomografia multislice e que mostravam no mínimo 200 citações de sua técnica em outros artigos originais, demonstrando a relevância destes. Foram excluídos estudos relacionados às imagens tridimensionais, que não são objetos desta revisão, além de índices que necessitem que o dentista utilize softwares ou outras ferramentas avançadas para realização da análise (exemplo: dimensão fractal).

\section{Resultados}

Foram selecionados três estudos ${ }^{9-11}$ de pesquisadores que desenvolveram índices para radiografias panorâmicas ou periapicais, que tiveram mais de 200 citações em artigos originais e que realizaram correlações com resultados significativos com a densidade óssea. O motivo para escolhermos artigos que tenham sido exaustivamente citados se deve ao fato de objetivarmos expor somente os índices de maior relevância e amplamente estudados na literatura. Foram também excluídas análises que envolviam a utilização de programas ou softwares, que, de alguma forma, dificultariam o seu emprego pelo cirurgião-dentista no dia a dia atarefado da rotina do consultório. A descrição resumida de cada estudo encontrase disponível na Tabela 1.

Tabela 1 - Descrição resumida dos principais índices radiomorfométricos utilizados em radiografias odontológicas, amplamente citados em outros estudos e com resultados significativos em relação à densidade óssea.

\begin{tabular}{l|c|c|c}
\hline Autores & Nome do índice & $\begin{array}{c}\text { Tipo de radiografia } \\
\text { utilizada }\end{array}$ & Resumo do índice \\
\hline Klemetti e colaboradores $^{9}$ & $\begin{array}{c}\text { Índice da cortical } \\
\text { mandibular }\end{array}$ & $\begin{array}{c}\text { Radiografia } \\
\text { panorâmica }\end{array}$ & $\begin{array}{c}\text { Índice qualitativo que classifica } \\
\text { o endósteo da cortical da } \\
\text { mandíbula em C1 (normal), } \\
\text { C2 (redução da densidade } \\
\text { mineral) e C3 (redução severa } \\
\text { da densidade mineral) de } \\
\text { acordo com a presença de } \\
\text { áreas radiolúcidas na cortical } \\
\text { da mandíbula. }\end{array}$ \\
\hline Taguchi e colaboradores ${ }^{10}$ & $\begin{array}{l}\text { Índice mentual e } \\
\text { mandibular cortical }\end{array}$ & $\begin{array}{c}\text { Radiografia } \\
\text { panorâmica }\end{array}$ & $\begin{array}{c}\text { Índice quantitativo que mede a } \\
\text { cortical da mandíbula. Quanto } \\
\text { menor a altura da cortical } \\
\text { da mandíbula, tanto maior a } \\
\text { probabilidade de o paciente ter } \\
\text { redução da densidade mineral } \\
\text { óssea. }\end{array}$ \\
\hline Lindh e colaboradores $^{11}$ & & Radiografia periapical & $\begin{array}{c}\text { Verifica o padrão trabecular } \\
\text { ósseo em radiografias } \\
\text { periapicais. Classifica as } \\
\text { trabéculas ósseas em classes } \\
1,2,3 \text { e 4. }\end{array}$ \\
\hline
\end{tabular}




\section{Discussão}

As análises e índices supracitados refletem a situação da densidade mineral óssea na mandíbula, permitindo o rastreamento de pacientes com redução da densidade mineral óssea. Para o adequado entendimento do processo associado à osteoporose, é primordial o entendimento da fisiologia relacionada ao tecido ósseo e remodelação óssea.

\section{CONSIDERAÇÕES FINAIS}

As consequências da osteoporose e outras doenças osteometabólicas não selimitam à área médica, havendo diversas implicações na odontologia. Dessa forma, é fundamental ao cirurgião-dentista avaliar criteriosamente a qualidade óssea, compreendendo os seus aspectos biológicos e radiográficos para um adequado planejamento do tratamento.

A avaliação qualitativa do trabeculado e da cortical óssea, assim como da espessura da cortical mandibular, é ferramenta útil que pode ser usada por cirurgiões-dentistas para rastrear a qualidade óssea dos seus pacientes. As limitações dessas análises estão relacionadas principalmente à experiência do profissional e da qualidade da imagem, devendo ser observadas com a devida cautela.

\section{REFERÊNCIAS}

1. Alford AI, Kozloff KM, Hankenson KD. Extracellular matrix networks in bone remodeling. Int J Biochem Cell Biol. 2015, Aug; 65: 20-31. https://www.ncbi.nlm.nih.gov/pubmed/?term=E xtracellular+matrix+networks+in+bone+remode ling. +Int+J+Biochem+Cell+Biol

2. Friedman AW. Important determinants of bone strength: beyond bone mineral density. J Clin Rheumatol. 2006, Apr; 12 (2): 70-7.

https://www.ncbi.nlm.nih.gov/pubmed/?term=F riedman+AW.+Important+determinants+of+bon e+strength $\% 3 \mathrm{~A}+$ beyond+bone+mineral+densit $y .+J+C l i n+R$ heumatol.
3. Hernandez CJ, Keaveny TM. A biomechanical perspective on bone quality. Bone. 2006, Dec; 39 (6): 1.173-81.

https://www.ncbi.nlm.nih.gov/pubmed/?term=Hern andez+CJ\%2C+Keaveny+TM.+A+biomechanical +perspective+on+bone+quality.+Bone.+2006\%3B

4. Pallagatti S., Parnami P., Sheikh S., Gupta D. Efficacy of Panoramic Radiography in the Detection of Osteoporosis in Post-Menopausal Women When Compared to Dual Energy X-Ray Absorptiometry. Open Dent J. 2017, Jun; 11: 350-9. https://www.ncbi.nlm.nih.gov/pubmed/?term=P allagatti+S\%2C+Parnami+P $\% 2 \mathrm{C}+$ Sheikh $+\mathrm{S} \% 2$ $\mathrm{C}+$ Gupta+D.+Efficacy+of+Panoramic+Radiogr aphy+in+the+Detection+of+Osteoporosis+in+P ost- Menopausal+Women+When+Compared+t o+Dual+Energy+X-Ray+Absorptiometry.

5. Cheade MCC ML, Arita ES, Watanabe PCA. Opportunistic screening for osteoporosis correlating the bone densities of jaws with multislice computed tomography for cervical vertebrae.

Clin Lab Res Dent. 2019, Jun: 1-6. https://doi.org/10.11606/issn.2357-8041. clrd.2019.155263

6. Munhoz L., Aoki EM, Cortes ARG, de Freitas CF, Arita ES. Osteoporotic alterations in a group of different ethnicity Brazilian postmenopausal women: An observational study. Gerodontology. 2018, Jun; 35 (2): 101-09. https://www.ncbi.nlm.nih.gov/pubmed/?term=M unhoz+Gerodontology

7. Kim OS, Shin MH, Song IH, et al. Digital panoramic radiographs are useful for diagnosis of osteoporosis in Korean postmenopausal women. Gerodontology. 2016, Jun; 33 (2): 185-92. https://www.ncbi.nlm.nih.gov/pubmed/?term=D igital+panoramic+radiographs+are+useful+for+ diagnosis+of+osteoporosis+in+Korean+postme nopausal+women.+Gerodontology

8. Choi IG, Munhoz L., Arita ES. Assessment of Osteoporotic Alterations in Brazilian Postmenopausal Women: A Retrospective Study. Journal of Clinical and Dental Research. 2018, May; 12 (5): ZC34-ZC37. doi: 10.7860/JCDR/2018/34529.11566

9. Klemetti E., Kolmakov S., Kröger H. Pantomography in assessment of the osteoporosis risk group. Scand J Dent Res. 1994, Feb; 102: 68-72. 
BASES CELULARES DA REMODELAÇÃo ÓSSEA E AVALIAÇÃo DE PACIENTES

COM REDUÇÃO DE DENSIDADE MINERAL ÓSSEA EM RADIOGRAFIAS ODONTOLÓGICAS

https://www.ncbi.nlm.nih .gov/pubmed/?term=P antomography+in+assessment+of+the+osteop orosis+risk+group.+Scand+J+Dent+Res

10. Taguchi A., Suei Y., Sanada M., et al. Validation of dental panoramic radiography measures for identifying postmenopausal women with spinal osteoporosis. AJR Am J Roentgenol. 2004, Dez; 183 (6): 1.755-60.

https://www.ncbi.nlm.nih.gov/pubmed/?term=V alidation+of+dental+panoramic+radiography+ measures+for+identifying+postmenopausal+w omen+with+spinal+osteoporosis.+AJR+Am+J+ Roentgenol.+2004

11. Lindh C., Petersson A., Rohlin M. Assessment of the trabecular pattern before endosseous implant treatment: diagnostic outcome of periapical radiography in the mandible. Oral Surg Oral Med Oral Pathol Oral Radiol Endod. 1996, Sep; 82 (3): 335-43. https://www.ncbi. nlm.nih.gov/pubmed/8884836

12. Florencio-Silva R., Sasso GR, Sasso-Cerri E., Simões MJ, Cerri PS. Biology of Bone Tissue: Structure, Function, and Factors That Influence Bone Cells. Biomed Res Int. 2015, Jul; 2015: 421746.

https://www.ncbi.nlm.nih.gov/pubmed/?term=Bi ology+of+Bone+Tissue $\% 3 \mathrm{~A}+$ Structure $\% 2 \mathrm{C}+\mathrm{Fu}$ nction $\% 2 \mathrm{C}+$ and + Factors + That+Influence+Bon e+Cells.+Biomed+Res+Int

13. Hadjidakis DJ, Androulakis II. Bone remodeling. Ann N Y Acad Sci. 2006, Dec; 1.092: 385-96. https://www.ncbi.nlm.nih.gov/pubmed/?term=H adjidakis+DJ\%2C+Androulakis+II.+Bone+remo deling.+Ann

14. Datta HK, Ng WF, Walker JA, Tuck SP, Varanasi SS. The cell biology of bone metabolism. J Clin Pathol. 2008, May; 61 (5): 577-87. https://www.ncbi.nlm.nih.gov/pubmed/?term=D atta $+\mathrm{HK} \% 2 \mathrm{C}+\mathrm{Ng}+\mathrm{WF} \% 2 \mathrm{C}+$ Walker+JA\%2C+T uck+SP\%2C+Varanasi+SS.+The+cell+biology +of+bone+metabolism.+J+Clin+Pathol

15. Arana-Chavez VE, Bradaschia-Correa V. Clastic cells: mineralized tissue resorption in health and disease. Int J Biochem Cell Biol. 2009, Mar; 41 (3): 446-50.

https://www.ncbi.nlm.nih. gov/pubmed/?term=Arana-
Chavez+VE\%2C+Bradaschia-Correa+V.+Clast ic +cells $\% 3 \mathrm{~A}+$ mineralized+tissue+resorption+in +health+and+disease.

16. Rucci N. Molecular biology of bone remodelling. Clin Cases Miner Bone Metab. 2008, Jan; 5 (1): 49-56.

https://www.ncbi.nlm.nih.gov/pubmed/?term=R ucci+N.+Molecular+biology+of+bone+remodelli ng.+Clin+Cases+Miner+Bone+Metab.+2008

17. Boyle WJ, Simonet WS, Lacey DL. Osteoclast differentiation and activation. Nature. 2003, May; 423 (6937): 337-42.

https://www.ncbi.nlm.nih.gov/pubmed/?term=0 steoclast+differentiation+and+activation.+Natu re. +2003

18. Jonasson G., Jonasson L., Kiliaridis S. Skeletal bone mineral density in relation to thickness, bone mass, and structure of the mandibular alveolar process in dentate men and women. Eur J Oral Sci. 2007, Apr; 115 (2): 117-23. https://www.ncbi.nlm.nih.gov/pubmed/?term=S keletal+bone+mineral+density+in+relation+to+t hickness $\% 2 \mathrm{C}+$ bone+mass $\% 2 \mathrm{C}+$ and +structure +of+the+mandibular+alveolar+process+in+den tate+men+and+women.+Eur+J+Oral+Sci.

19. Lindh C., Horner K., Jonasson G., et al. The use of visual assessment of dental radiographs for identifying women at risk of having osteoporosis: the OSTEODENT project. Oral Surg Oral Med Oral Pathol Oral Radiol Endod. 2008, Aug; 106 (2): 285-93.

https://www.ncbi.nlm.nih.gov/pubmed/?term=Li ndh $+\mathrm{C} \% 2 \mathrm{C}+$ Horner+K\%2C+Jonasson+G\%2C + et+al.+The+use+of+visual+assessment + of $+d$ ental+radiographs+for+identifying+women+at+ risk+of+having+osteoporosis $\% 3 \mathrm{~A}+$ the+OSTEO DENT+project.

20. Jonasson GB, Sundh V., Hakeberg M., Ahlqwist M., Lissner L., Hange D. Evaluation of clinical and radiographic indices as predictors of osteoporotic fractures: a 10-year longitudinal study. Oral Surg Oral Med Oral Pathol Oral Radiol. 2018, May; 125 (5): 487-94. https://www.ncbi.nlm.nih.gov/pubmed/?term=E valuation+of+clinical+and+radiographic+indic es+as+predictors+of+osteoporotic+fractures $\%$ $3 \mathrm{~A}+\mathrm{a}+10$-year+longitudinal+study.+Oral+Surg +Oral+Med+Oral+Pathol+Oral+Radiol 
21. Jonasson G., Jonasson L., Kiliaridis S. Changes in the radiographic characteristics of the mandibular alveolar process in dentate women with varying bone mineral density: a 5 -year prospective study. Bone. 2006, May; 38 (5): 714-21. https://www.ncbi.nlm.nih.gov/pubmed/?term=C hanges+in+the+radiographic+characteristics+o $f+$ the+mandibular+alveolar+process+in+dentat e+women+with+varying+bone+mineral+density $\% 3 A+a+5$-year+prospective+study.

22. Taguchi A., Tanimoto K., Akagawa Y., Suei Y., Wada T., Rohlin M. Trabecular bone pattern of the mandible. Comparison of panoramic radiography with computed tomography. Dentomaxillofac Radiol. 1997, Mar; 26 (2): 85-89. https://www.ncbi.nlm.nih.gov/pubmed/9442622

23. Munhoz L. Cl, Miura DK, Watanabe PCA, Arita ES. Bone mineral density and man- dibular osteoporotic alterations in panoramic radiographs: Correlation by peripheral bone densitometry in men. Indian J Den Res. 2019. [ahead of print] doi: 10.4103/ijdr.IJDR_440

24. Calciolari E., Donos N., Park JC, Petrie A., Mardas N. Panoramic measures for oral bone mass in detecting osteoporosis: a systematic review and meta-analysis. J Dent Res. 2015, Mar; 94 (3): 17S-27S.

https://www.ncbi.nlm.nih.gov/pubmed/?term=C alciolari+E\%2C+Donos+N\%2C+Park+JC\%2C+ Petrie $+\mathrm{A} \% 2 \mathrm{C}+$ Mardas $+\mathrm{N} .+$ Panoramic+measu res+for+oral+bone+mass+in+detecting+osteop orosis $\% 3 \mathrm{~A}$

Submetido em: 6-10-2019

Aceito em: 17-3-2020 